\title{
A CONCEPÇÃO DE DIGNIDADE HUMANA EM RONALD DWORKIN: UM PROBLEMA DE ÉTICA PRÁTICA
}

\author{
Evandro Barbosa ${ }^{1}$ \\ Universidade Federal de Pelotas (UFPEL) \\ (D) https://orcid.org/0000-0002-5695-3746 \\ Thaís Cristina Alves Costa ${ }^{2}$ \\ Universidade Católica de Pelotas (UCPEL) \\ (D) https://orcid.org/0000-0002-1274-0431
}

\section{RESUMO:}

Trata-se de abordar a concepção dworkiniana de dignidade humana a partir de sua obra Domínio da Vida (1993). O intuito deste texto é delimitar conceitualmente sua concepção de dignidade humana para, posteriormente, analisar a importância dessa concepção para a solução de problemas de ordem prática, tais como o aborto e a eutanásia.

PALAVRAS-CHAVE: Dignidade humana; Sacralidade da vida; Autonomia; Aborto; Eutanásia.

\section{THE CONCEPTION OF HUMAN DIGNITY IN RONALD DWORKIN: A PROBLEM OF PRACTICAL ETHICS.}

\begin{abstract}
:
This paper discuss the concept of human dignity for Dworkin in his work Life's Dominion (1993). The purpose of this is delimit conceptually his conception of human dignity to subsequently analyze the importance of this

\footnotetext{
${ }^{1}$ Doutor em filosofia pela Pontifícia Universidade Católica do Rio Grande do Sul (PUCRS), Rio Grande do Sul - Brasil. Desenvolveu estágio pós-doutoral na Universidade Federal de Pelotas (UFPEL), Rio Grande do Sul - Brasil e foi Visiting Professor na Yale University - EUA, sob orientação do professor Stephen Darwall, com bolsa CAPES. Professor de Filosofia da Universidade Federal de Pelotas (UFPEL), Rio Grande do Sul Brasil. E-mail: evandrobarbosa2001@yahoo.com.br.

${ }^{2}$ Mestre em Filosofia pela Universidade Federal de Pelotas (UFPEL), Rio Grande do sul Brasil. Estudante do curso do direito na Universidade Católica de Pelotas (UCPEL). Email: costa.thaisalves@gmail.com.
} 
conception for the solution of practical problems, such as abortion and euthanasia.

KEYWORDS: Human dignity; The sacredness of life; Autonomy; Abortion; Euthanasia.

\section{Introdução}

O objetivo desse artigo é analisar a concepção de dignidade humana no pensamento de Ronald Dworkin. Para isso, será analisado o pensamento dworkiniano tendo como ponto de partida a obra Domínio da vida (1993), na qual o conceito de dignidade humana é desenvolvido para a solução de problemas de ética aplicada. Neste texto, a questão por excelência é compreender em que medida nos é permitido matar ou lançar mão de nossa própria vida nos momentos em que a vida parece ter perdido a sua dignidade. Assim, o problema da dignidade humana surge como um complemento ao que Dworkin chama santidade da vida. Para a devida compreensão apontaremos, primeiramente, uma definição conceitual para o termo (distinguindo-o de sacralidade da vida e da noção de valor intrínseco derivado daquela) para, posteriormente, estabelecer sua aplicação em casos concretos de ordem prática, a saber: a eutanásia e o aborto.

\section{0 conceito de dignidade humana em Dworkin}

Antes de tudo, é importante compreendermos que Dworkin possui uma visão secularizada de dignidade humana pautada em dois princípios que o sustentam. Primeiro, existe o princípio do valor intrínseco, o qual sustenta que a vida humana possui valor objetivo e, por isso, todas as ações da vida humana são analisadas por todos em termos de querer (want) ou reprovar (deplore). Segundo, há o princípio da responsabilidade pessoal segundo o qual todos os indivíduos são responsáveis pelo desenvolvimento de sua própria potencialidade. Por sua vez, estes dois princípios são esclarecidos pelo valor da equidade e da liberdade ${ }^{3}$.

Segundo Dworkin, o direito à dignidade pode ser entendido como “(...) o direito de viver em condições quaisquer que sejam, nas quais o amor - próprio é possível ou pertinente (...) direito de não ser vítima da

\footnotetext{
${ }^{3}$ Woods no capítulo Globalization, human rights and the environment de sua obra Human Rights and Environmental Sustainability (2010) desenvolve de forma mais acurada a influência destes dois elementos tidos por ele como 'esclarecedores' para a concepção de dignidade humana em Dworkin. Ao falar da equidade e liberdade Wood afirma que, "the difficulty with these principles as na explaination of human dignity is that Dworkin does not explain, so much as assert as fact, the claim that human life has objective value, which dignity is itself invoked to explain in human rights documents." (WOOD, 2010, p. 32).
} 


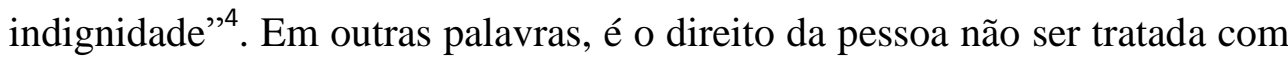
desrespeito dentro da comunidade e cultura na qual vive. Isso explica porque, por exemplo, devemos tratar de forma digna presidiários ou, na forma negativa, porque exista a impossibilidade de tratá-los de maneira considerada cruel. Nesse sentido, o pressuposto da dignidade enquanto regulador das ações dos indivíduos e do Estado exige que a comunidade lance mão de qualquer recurso necessário para assegurá-lo. No caso do presidiário, mesmo que a pessoa seja privada de liberdades (limitação da autonomia), isso não nos autoriza a um tipo de tratamento que comprometa sua condição de dignidade ao impor tortura, trabalho escravo, privação de alimentação, assistência jurídica, alojamento com mínimo de infraestrutura, etc.

Nessa perspectiva, o tratamento indigno pode proporcionar a perda do amor-próprio, o que Dworkin considera a pior privação que o sujeito pode sentir. No seu entender, a dignidade possuí duas vozes conectadas: uma voz passiva e uma voz ativa ${ }^{5}$. A voz ativa é a dignidade que nós exigimos que os outros tenham para conosco, pressupondo-se também que “(...) as pessoas se importam e devem importar-se com sua própria dignidade" . Por outro lado, a voz passiva é a dignidade que os outros requerem que tenhamos com eles. Logo, a concepção de dignidade dworkiniana exige que o outro seja tratado com dignidade, na mesma medida em que eu também exijo ser tratado.

Dentre as formas de indignidade, a pior delas seria infringir a indignidade a uma pessoa de forma a torná-la indiferente de outras indignidades, ou seja, tornar o outro alheio à situação de indignidade em que vive. Nesse sentido, o não reconhecimento da indignidade pela vítima é cruel, inclusive, para os demais indivíduos que reconhecem a privação daquele e o percebem como totalmente violado/ferido em seu valor intrínseco. De acordo com Dworkin, o direito à dignidade é

[...] o direito a que os outros reconheçam os seus verdadeiros interesses críticos: que reconheçam que ela é o tipo de criatura cuja posição moral torna intrínseca e objetivamente importante o modo como sua vida transcorre. A dignidade é um aspecto central do valor [...] a importância intrínseca da vida humana ${ }^{7}$.

Para Dworkin, a vida humana possui, inevitavelmente, valor intrínseco do qual é sagrada. Nesse sentido, Dworkin retoma a concepção de dignidade humana kantiana, utilizando-se de uma leitura comum ao

\footnotetext{
${ }^{4}$ DWORKIN, 2009, p.333.

${ }^{5}$ Cf. Ibid., p. 336.

${ }^{6}$ Ibid., p.339.

${ }^{7}$ Ibid., p. 337.
}

A concepção de dignidade humana em Ronald Dworkin: um problema de ética prática - Evandro Barbosa; Thaís Cristina Alves Costa 
paradigma contemporâneo de dignidade ${ }^{8}$, na qual a ideia de dignidade em Kant seria o valor intrínseco a partir do qual nós devemos respeitar os outros. Dworkin parte do imperativo categórico e do princípio segundo o qual as pessoas devem ser tratadas como fins, nunca simplesmente como meios, para ressaltar a sua concepção de dignidade humana. Segundo ele, “(...) esse princípio não exige que as pessoas nunca sejam colocadas em desvantagem com o objetivo de oferecer vantagens a outras, mas sim que nunca sejam tratadas de maneira que se negue a evidente importância de suas próprias vidas" $"$. Dessa forma, não haveria problema em uma pessoa lançar mão de vantagens próprias para garantir a dignidade do outro. Além disso, Dworkin reafirma sua visão não metafísica ao propor uma concepção secularizada de dignidade humana que vai ao encontro das visões contemporânea de direitos humanos não contextualizadas, nem ornamentados ontologicamente ${ }^{10}$. Como afirma Woods:

A secular notion of inherent human dignity would have to assert that there is meaning and worth in humanity in the context of a view of the universe as meaningless or at least a view that is agnostic about the possibility of meaning. Humanity, then, is the only solid reference point $^{11}$.

\section{Estudo de caso: euthanasia}

Além dos esclarecimentos conceituais necessários, o uso de sua concepção de dignidade humana para questões de ética aplicada ajudam a esclarecer sua proposta. Passemos agora ao seu uso na problemática

\footnotetext{
${ }^{8}$ Sensen na obra Kant on human Dignity, afirma que há duas maneiras de interpretar a dignidade humana em Kant, uma é a concepção baseada no paradigma contemporâneo de dignidade, a qual é entendida como um conceito com fortes implicações morais em que o valor inerente do indivíduo é visto como dever de respeito ao outro. Ao passo que a outra interpretação é a concepção tradicional de dignidade, na qual, a dignidade em Kant é concebida como sublimidade (elevação) e não como um valor por si que rende direitos. Nesse sentido, a dignidade da humanidade refere-se a ideia de que o ser humano por ser livre, está acima do restante da natureza (sentido aristocrático) Essa última concepção é para Sensen a interpretação adequada do pensamento kantiano.

${ }^{9}$ DWORKIN, op cit., p. 339.

${ }^{10}$ Perry coloca algumas dificuldades ao pensamento de Dworkin neste ponto: "Dworkin seems to be using 'sacred' in what we can call a weak, or 'subjective', sense - something (e. g., a human life) is sacred because, or in the sense that, it inspires awe in us and we attach great value to it - rather than in the Strong, or 'objective', sense - something is sacred and therefore it inspires awe in us and we attach great value to it." (PERRY, 1998, p. 28)

${ }^{11}$ WOODS, 2010, p. 32
} 
envolvendo a eutanásia ${ }^{12}$. Ao lidar com este problema, Dworkin afirma que antes de qualquer coisa deve-se considerar o estado do paciente: $a$. ele está consciente e é capaz de autonomia; $b$. ele está consciente, porém não é competente fisicamente para exterminar a sua vida. Nessa situação, ele precisaria da ajuda de outra pessoa para 'garantir' sua morte. É o caso de eutanásia ativa, em que o médico auxilia o paciente no seu intento de pôr um fim à vida; $c$. o paciente está inconsciente, $i$. e., em estado vegetativo ou em coma persistente, de modo a não sentir e nem responder a estímulos externos. Por sua vez, cada situação em particular precisa, necessariamente, levar em consideração três elementos para a tomada de decisão em cada caso: $a$. autonomia, $b$. interesses fundamentais do paciente e $c$. sacralidade da vida.

A (a) autonomia é o paciente ser capaz de agir com discernimentos e autodeterminação. Para tanto, a tomada de decisão livre e sensata do indivíduo requer que ele seja informado pelo médico sobre sua real condição de vida e para que possa escolher o que considerar mais conveniente naquele momento. Além disso, o paciente tem também seus interesses fundamentais (b), ou seja, aquilo que realmente importa para ele, estando ele no momento capaz ou não de decidir.

Por sua vez, a $(c)$ sacralidade da vida é o elemento da sacralidade humana. Em outras palavras, é a vida humana considerada como intrinsecamente valiosa. Nesse sentido, se assegurado o valor intrínseco da vida do paciente, pode-se ir contra seus interesses, pois a vida em si teria valor sagrado e inquestionável. Acerca disso, afirma Dworkin: “(...) uma coisa é intrinsecamente, se seu valor for independente daquilo que as pessoas apreciam, deseja ou necessitam, ou do que é bom para elas"13. O princípio da santidade da vida humana é visto com muitas ressalvas por Dworkin, ora porque não respeita a autonomia do paciente ou interesse da família, ora porque visa à quantidade de vida, independente da qualidade. Nesse sentido, o valor intrínseco da vida significa o respeito pela vida em si

\footnotetext{
${ }^{12} \mathrm{O}$ primeiro pensador a fazer uso do termo eutanásia foi Bacon em 1623, na obra Historia vitae et mortis, que o considerava como "tratamento adequado as doenças incuráveis". De maneira geral, entende-se por eutanásia quando uma pessoa causa deliberadamente a morte de outra que está mais fraca, debilitada ou em sofrimento. Neste último caso, a eutanásia seria justificada como uma forma de evitar um sofrimento acarretado por um longo período de doença. Tem sido utilizado, de forma equivocada, o termo Ortotanásia para indicar este tipo de eutanásia. Esta palavra deve ser utilizada no seu real sentido de utilizar os meios adequados para tratar uma pessoa que está morrendo. O termo eutanásia é muito amplo e pode ter diferentes interpretações. Um exemplo de utilização diferente da que hoje é utilizada foi a proposta no século XIX, os teólogos Larrag e Claret, na obra Prontuários de Teologia Moral, de 1866. Eles utilizavam eutanásia para caracterizar a "morte em estado de graça”. (Cf. GOLDIM, José Roberto. Eutanasia. Bioética/UFRS. Disponível em http://www.bioetica.ufrgs.br/eutanasi.htm. Acesso em 20/07/2014.
}

${ }^{13}$ DWORKIN, op cit., 252. 
mesma, desinteressada de qualquer fato ou fundamento. Por ser assim, devese preservar a vida indeterminadamente, mesmo quando este não for o interesse do paciente ou de seus familiares.

Porém, esta manutenção da vida se contrapõe a visão de que se deve respeitar o limite natural da mesma, o que se reflete no correto significado do que é ter uma vida (manutenção) ou morte (eutanásia) digna. Dworkin leva em consideração a situação da eutanásia quando a situação em que o indivíduo se encontra pode ser considerada indigna. A eutanásia que ocorre quando o paciente tem autonomia e meios físicos para sua realização é considerado um caso clássico do suicídio, pelo qual o paciente da cabo da própria vida. Obviamente, esta visão diverge do posicionamento kantiano de um Imperativo Categórico segundo o qual, nem se eu fosse o último ser humano da Terra, em total desgraça, me seria concedido o "privilégio" de tirar a própria vida. Entretanto, quando mudamos o cenário de fundo e o sujeito que deseja o suicídio o faz via recursos alheios, então temos caracterizada um situação em que um indivíduo auxilia outro a tirar sua própria vida. Este terreno é mais delicado, basta lembrarmos dos inúmeros exemplos que Dworkin oferece ao longo do seu texto, especialmente o caso do Dr. Morte ${ }^{14}$.

A segunda hipótese diz respeito ao paciente que deseja terminar com sua vida, porém não dispõe dos meios físicos necessários. É o caso da eutanásia ativa, em que o paciente é auxiliado, na maioria dos casos, pelo médico ou até por familiares que reconhecem seu sofrimento ou seu desejo professo de não viver assim. No caso do médico, após este constatar que não há mais tratamento capaz de fazê-lo retornar de sua condição enferma e que a morte não tardará a vir (ou não), este pode praticar a eutanásia ativa ou “(...) um homicídio praticado com o intuito de livrar o doente, irremediavelmente perdido, dos sofrimentos que o atormentam" ${ }^{\text {"15. Em }}$ outras palavras, livrá-lo da situação indigna em que ele se encontra. Como se observa, a questão é controversa e não faltam bons argumentos para os dois lados: pessoas que desejam continuar viva, ou seja, lutar até aonde seja possível para manter-se neste mundo ou implorar pela autorização de abandoná-lo.

A terceira hipótese que Dworkin levanta diz respeito aos pacientes que estão em algum tipo de estado de inconsciência. Nesse caso, como proceder? Devemos autorizar um procedimento de eutanásia seguindo outras indicações que não a autonomia do paciente? Nestes casos, a família costuma ter papel determinante para a escolha, tanto pelo sim com pelo não. Normalmente, quando do sim, familiares se reúnem com a junta médica que lhes explicam a situação e o fim inevitável que aguardava a vítima para

\footnotetext{
${ }^{14}$ Médico de Detroit que confeccionou uma máquina para que pessoas, em estado terminal, pudessem realizar suicídio medicamente assistido.

${ }^{15}$ Ibid., p. 263.
} 
decidir o que fazer. A decisão de desligar o aparelho que mantém o indivíduo vivo é chamada de eutanásia passiva ou ortotanásia. Nesse caso, a justificativa estaria dada pelo "momento natural da morte", não fazendo uso de meios artificiais para protelar uma situação não-natural. Este é o argumento daqueles que afirmam que dignidade da vida é também respeitar este momento natural da morte, ou seja, eutanásia negativa não seria moral e nem juridicamente errada.

A dúvida para este caso fica por conta da remota possibilidade do paciente voltar de seu estado vegetativo, contrariando a ciência. Ou, então, diz-se que esta situação tem o agravante de que o paciente não estaria exercendo sua autonomia e que a decisão de desligar os aparelhos foi dada de forma arbitrária. Do que nos interessa por ora, Dworkin apresenta a ideia de um valor intrínseco secular à vida como fazendo frente a tudo e, por conta disso, solaparia qualquer justificação de um procedimento eutanásico. Logo, a vida deveria ser protegida e resguardada em quaisquer circunstâncias. Entretanto, Dworkin apresenta um argumento interessante: ele afirmar que o mesmo princípio da sacralidade da vida pode ser evocado por aqueles que desejam pôr fim à sua vida respeitando o processo natural de qualquer ser vivo. Quer dizer, manter-se vivo por meios artificiais não parece ser tão mais respeitoso à sacralidade da vida e à dignidade do que a deixar seguir o seu curso natural, ou seja, permitir sua morte. Segundo Dworkin,

\begin{abstract}
Os que desejam uma morte prematura e serena para si mesmo ou para seus parentes não estão rejeitando ou denegrindo a santidade da vida; ao contrário, acreditam que uma morte mais rápida demonstra mais respeito para com a vida do que uma morte protelada. Uma vez mais, os dois lados do debate sobre eutanásia compartilham uma preocupação com a santidade da vida; estão unidos por esse valor e só divergem sobre a melhor maneira de interpretá-lo e respeitá-lo ${ }^{16}$.
\end{abstract}

A cartada final de Dworkin é apelar para uma questão de qualidade, em detrimento da quantidade, de vida ao retomar o conceito de dignidade humana, no sentido de se respeitar o valor inerente de nossas próprias vidas. Segundo ele:

é imperdoável ignorar por completo a grande importâncias dessas questões [...] deixar o destino de um amigo inconsciente ou demenciado nas mãos de estranhos de avental branco, com base no pressuposto de que não mais lhe importa o que possa acontecer [...] Para resumir: o maior insulto à sacralidade da

${ }^{16}$ Ibid., p. 341

A concepção de dignidade humana em Ronald Dworkin: um problema de ética prática - Evandro Barbosa; Thaís Cristina Alves Costa 


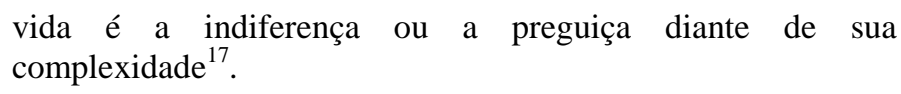

Para Dworkin, o que está em jogo é a dignidade humana e essa dignidade preza a liberdade de consciência para as nossas escolhas, assim como o compromisso comunitário para questões que envolvem esta sacralidade da vida humana. Independente de nosso ponto de vista em relação à eutanásia, o que importa para o filósofo é que tenhamos o nosso direito de decidir por nós mesmos (autonomia), respeitando nossos interesses e a dignidade humana inerente a cada humano.

\section{Estudo de caso: aborto}

Outro debate de Dworkin empreendido a partir das questões referentes à dignidade humana é o tema do aborto. No entender do filósofo, as discussões sobre as principais questões bioéticas se constituem em desacordo permanente pelo fato de estarem deslocadas de seu correto eixo de discussão. É o caso do aborto, cujo debate geralmente ocorre em saber se ele é ou não moralmente permitido a partir da questão de saber se o feto é ou não uma (a) pessoa e se ele (b) possui interesses e direitos. No entende de Dworkin, esta é uma questão derivativa e deveríamos retroceder e questionar algo anterior e mais fundamental: a saber, se a vida possui ou não valor intrínseco. A consequência é uma posição realista de que "[...] o valor seria uma propriedade das próprias coisas independentemente do que as pessoas possam pensar ou desejar"18.

Esta é o que ele chama de distinção crucial para o debate. Existem aqueles que encaram o aborto de um modo derivativo, ou seja, pressupõe os direitos e os interesses do feto. Por outro lado, há aqueles que possuem uma abordagem independente e levam em conta o caráter sagrado e o valor intrínseco da vida. Dworkin inclina-se para o segundo grupo, justamente por acreditar que não faz sentido alguém possuir interesses próprios a não ser que possua consciência, e que tais interesses devem ser aqueles presentes no momento do aborto, e não aqueles que eventualmente se desenvolverão caso o aborto não seja feito. Por isso, o aborto deve ser analisado sob a ótica do valor intrínseco da vida, independentemente de qualquer interesse ou direito que o feto possa ter. Definir se ele é uma pessoa é ambíguo e de certa forma obscuro tanto juridicamente, quanto para a medicina, desembocando em um debate sem nenhuma utilidade prática. Por isso, o ponto de partida para Dworkin é retratar a sacralidade e dignidade da vida a partir de uma consideração sobre valor intrínseco, fazendo três distinções básicas:

\footnotetext{
${ }^{17}$ Ibid., p. 343

${ }^{18}$ Ibid., p. 101.
}

A concepção de dignidade humana em Ronald Dworkin: um problema de ética prática - Evandro Barbosa; Thaís Cristina Alves Costa 
a. O valor instrumental que depende da utilidade e da capacidade de gerar meios para obtenção de outras coisas;

b. O valor subjetivo: quando uma coisa é especialmente valiosa para uma pessoa;

c. E, por fim, o valor intrínseco que é quando uma coisa tem valor independente do que as pessoas apreciam ou do que é bom para elas;

Para a discussão sobre o aborto é a preocupação com o valor intrínseco que realmente interessa em sua determinação. Dworkin faz uma comparação com as obras de arte: assim como grandes obras de arte que, acima dos gostos pessoais de cada um, a humanidade procura preservar com afinco, a vida tem um caráter sagrado, ou seja, inviolável e intrinsecamente valioso. Não é uma questão incremental, mas de valorização e proteção uma vez que a vida já tenha começado. Dworkin entende o "sagrado" no sentido de inviolável e não precisa, necessariamente, ter uma conotação religiosa. Dessa forma, tal sacralidade pode ser atribuída a uma coisa de dois modos distintos: (i.) por designação, em que o sagrado conferido é a animais, amuletos e objetos patrióticos ou (ii.) por gênese, quando algo passa a ser sagrado não pelo que é especificamente, mas pela maneira que surgiu ou passou a existir ${ }^{19}$.

\section{Considerações finais}

Dworkin trata do problema da dignidade humana discutindo as condições indignas que envolvem as relações entre os indivíduos. Nesse caso, podemos verificar as condições de voz ativa da dignidade de modo negativo, quando um indivíduo compromete sua dignidade e, automaticamente, nega o valor intrínseco da vida humana. Do mesmo modo, a voz passiva da dignidade é afetada quando o indivíduo está sofrendo uma violação de sua dignidade causada por outrem. Em ambas as condições percebemos como elemento comum a exigência de respeito (inclusive de auto-respeito) para com o valor intrínseco da vida humana, tendo em vista que condições de indignidade (seja autoinfligida, seja infligida por outro) limitam o desenvolvimento de projetos particulares de vida.

Além disso, Dworkin aborda o problema da autonomia do indivíduo afirmando que este possui dois tipos de interesse: interesse de experiência e interesse crítico. $\mathrm{O}$ primeiro diz respeito aos prazeres simples de uma boa

\footnotetext{
${ }^{19}$ Para saber mais acerca da distinção entre valor intrínseco e valor incremental, confira a página 102 da obra Domínio da vida de Dworkin.
}

A concepção de dignidade humana em Ronald Dworkin: um problema de ética prática - Evandro Barbosa; Thaís Cristina Alves Costa 
vida, tais como comer, ver um bom filme, etc., ao passo que os interesses críticos envolvem a satisfação de que a vida seja genuinamente melhor a partir de juízos críticos e não meras preferências sobre experiências. Tais interesses possuem uma conexão direta com aspectos relacionais e intersubjetivos para o ethos dos sujeitos, o que não permite certos tipos de reducionismos ao estilo de um equivocado entrelaçamento entre interesses de experiência e interesses críticos. Por isso, interesses críticos são os únicos genuinamente capazes de sustentar uma concepção de dignidade humana que transcende elementos contingentes que cercam a vida humana.

Dworkin compreende que a inviolabilidade da vida é um valor comum a todos os seres humanos por sua condição intrínseca, por isso as questões práticas - tais como aborto e eutanásia - mudam o eixo da reflexão da vida enquanto valor universal (intrínseco) para a vida enquanto bem jurídico-constitucional. Dessa forma, enquanto um liberal, Dworkin centraliza suas preocupações sobre a questão da dignidade para as zonas limítrofes do início e do fim da vida humana (aborto e eutanásia), de modo que a dignidade da pessoa humana enceta para um tipo de liberdade individual (que favorece a execução e o estabelecimento dos interesses críticos) e na ausência de coerção injusta através de um sistema jurídico capaz de comportar estas condições de autonomia e dignidade humana.

Sendo assim, ao examinar o conteúdo da dignidade, não é de estranhar porque Dworkin tem sua base dada a partir da filosofia prática kantiana - especialmente nas obras Fundamentação da metafísicas dos costumes e Metafísica dos costumes (detidamente, Doutrina do direito) -, na medida em que o ser humano não deve ser tratado na condição de instrumentalidade.

É possível concluir que a ideia de dignidade defendida por Dworkin é pautada no valor intrínseco do ser humano, bem como em seu direito de ser considerado como um fim em si mesmo (não instrumentalização). Sob essa perspectiva, a ideia de dignidade pode sustentar o argumento pró ou contra o aborto, a eutanásia, o suicídio entre outros problemas de ética aplicada. Importa ressaltar que, para Dworkin, essa dignidade deve embasar os princípios jurídicos que constituíram o direito como integridade no Estado democrático de direito. No seu caso, a ideia de não tratar o outro indignamente requer que adotemos uma concepção de justiça liberaligualitária que garanta o mínimo suficiente para a sobrevivência social do indivíduo. É nesse sentido que ocorre um entrelaçamento entre três diferentes esferas (ética, jurídica e política) no pensamento de Dworkin a partir da concepção de dignidade humana. Dessa forma, a dignidade estará presente nos princípios jurídicos, na mesma medida em que deve embasar a justiça social da igualdade de recursos e corroborar (ou não) com uma visão de ética prática que envolve polêmicas como o aborto e a eutanásia. 


\section{Referências bibliográficas}

BACON, Francis. The history of life and death, or the second title in the natural and experimental history for the building up of Philosophy, which is the third part of the Great Instauration. The Oxford Francis Bacon. Oxford: Oxford University Press, 2007.

DWORKIN, Ronald. A matter of principle. London: Harvard University Press, 1985.

. Domínio da vida. São Paulo: Martins Fontes, 2009.

. Life's Dominion: An Argument about Abortion, Euthanasia, and Individual Freedom. New York: Vintage Books, 1993.

. Sovereign Virtue: The Theory and Practice of Equality. London:

Harvard University Press, 2002. 1977. . Taking rights seriously. Cambridge: Harvard University Press,

GOLDIM, José Roberto. Eutanasia. Bioética/UFRS. Disponível em http://www.bioetica.ufrgs.br/eutanasi.htm. Acesso em 20/07/2014.

KANT, Immanuel. A metafisica dos Costumes. Trad. Edson Bini. São Paulo: Edipro, 2003.

. Fundamentação da metafísica dos costumes. Tradução de Paulo Quintela. Lisboa: Edições70, 1960.

PERRY, M. The Idea of Human Rights: Four Inquiries. Oxford: Oxford University Press, 1998.

- Perry, M. The Gospel According to Dworkin. Constitutional Commentary, 11ed. Winter, 1994.

SENSEN, O. Kant on Human Dignity. Berlim: De Gruyter, 2011.

WOODS, K. Human Rights and Enviromental Sustainability. Gloucestershire: Edward Elgar Publishing limited, 2010.

Contribuição dos autores:

Os autores Evandro Barbosa e Thaís Cristina Alves Costa participaram da discussão, revisão e redação do artigo. Todos os autores aprovaram a versão final do texto. 